\title{
Dual dynamics of promises, and waiting games around emerging nanotechnologies
}

\author{
Alireza Parandian ${ }^{\mathrm{a} *}$, Arie Rip ${ }^{\mathrm{b}}$ and Haico Te Kulve ${ }^{\mathrm{b}}$ \\ ${ }^{a}$ Technology Dynamics and Sustainable Development, Delft University of Technology, Delft, The Netherlands; \\ ${ }^{b}$ Science, Technology and Policy Studies, University of Twente, Enschede, The Netherlands
}

\begin{abstract}
Newly emerging science and technologies (NEST) are shaped by dynamics of promises. There is a paradoxical effect: diffuse and open-ended promises are forceful in policy discourse, but may hinder the realisation of these promises. Innovation actors are reluctant to invest in concrete developments because the promises are open-ended, and eventual demand is not articulated. This is a structural issue, and leads to 'waiting games' in which actors are entangled. We show how the occurrence of waiting games is linked to dual dynamics of promises in two fields where nanotechnology offers an open-ended ('umbrella') promise: organic and large area electronics and nano-enabled drug delivery. Based on such understanding of dynamics, our scenario exercises explored strategies to overcome waiting games.
\end{abstract}

Keywords: umbrella promises; promise-requirement cycles; waiting games; nanotechnology; organic and large area electronics; nano-enabled drug delivery; industry structure

\section{Introduction}

Newly emerging sciences and technologies (NEST) are accompanied by promises about their interest, performance and societal effects. At the same time, there are uncertainties about eventual performance and embedding in society. Addressing such uncertainties in strategic management and policy requires estimates of future developments, but also insight in the present situation and the forces shaping the ongoing dynamics, ranging from industry structures and governance regimes to less tangible but still forceful cultural factors.

These observations are uncontroversial. This paper adds to them by drawing attention to a paradox. New technologies like nanotechnology are surrounded by big promises, envisioning a third industrial revolution, environmental remediation and human enhancement. This 'halo' mobilises policy actors, industrialists and publics. ${ }^{1}$ At the same time, the existence of these promises can be an obstacle to the realisation of these envisaged benefits because of their diffuse and open-ended nature: this makes actors uncertain about directions to go and thus creates reluctance to invest in concrete developments. To highlight that this is a structural problem, we will speak of "waiting games'.

\footnotetext{
*Corresponding author. Email: ar.parandian@gmail.com
} 
When tracing developments in two fields with strong nanotechnology promises, organic large area electronics (OLAE) and nanotechnology-enabled targeted drug delivery, we encountered a striking phenomenon: the continuing reluctance of many actors to invest money and effort in developments, despite recognising the promises. Thus, promises are not turned into requirements that guide concrete development trajectories (cf. Van Lente 1993; Van Lente and Rip 1998, on promise-requirement cycles).

Clearly, there are two different promise dynamics: those of big but open-ended promises, which we call 'umbrella promises', and the more concrete promise-requirement cycles. They are not independent, and one can speak of dual dynamics of promises. ${ }^{2}$

The first part of the paper will develop this observation conceptually. The pattern (or de facto arrangement) that we are interested in is the waiting game linked to dual dynamics of promises. We argue that this is a recurrent pattern, over and above the waiting strategies that different actors may follow. In the second part of the paper, we will offer empirical data from our two fields, showing that there are indeed waiting games driven by the force of open-ended promises. In addition, we will briefly discuss how different kinds of actors and actor-collectives address waiting games.

The issue of waiting games linked to dual dynamics of promises is felt and recognised by actors, yet surprisingly has received little scrutiny in the literature. ${ }^{3}$ The understanding we offer of these processes and patterns can be used to develop management and governance intelligence.

\section{Conceptualisation: dual dynamics of promises and waiting games}

When developing our overall conceptualisation and considering different types of promise dynamics, we will not pay much attention to concrete actors and contexts. These are important. Researchers, firms, governmental and non-governmental actors play different roles and will perceive - and voice - expectations differently. In addition, actors are tied up in a web of relationships with each other, which enables and constrains their actions and interactions, independent of promises of emerging technologies. Although such broader aspects will be backgrounded to some extent in the discussion of our conceptual framework, they will be visible in our case studies.

For our conceptual framework we can build on the growing literature on sociology of expectations (or expectation statements) in innovation processes and the embedding of new and emerging science and technologies in society (Van Lente 1993; Van Lente and Rip 1998; Brown, Rappert, and Webster 2000; Brown and Michael 2003; Konrad 2004; Borup et al. 2006). For newly emerging science and technology (NEST), expectations are functionally important because it is through them that future value of technological options are articulated and to some extent becomes stabilised. In general, expectations motivate action to intervene in socio-technical networks and transform the current 'state of the world' as economists would say. ${ }^{4}$ Expectations, when shared, allow some coordination, and there are now attempts at joint coordination of emerging technologies and their future application, as in European Technology Platforms. ${ }^{5}$

\section{Umbrella promises}

The general perspective is well established by now. What has got less attention is that there are different patterns of dynamics of promises, and what the differences imply in the real world, including the paradoxical situation of big promises leading to waiting games. Kornelia Konrad's $(2004,2006)$ work is an exception, and we have been inspired by her analysis of, what we label as, the 'umbrella promise' of the information super highway in the early 1990s, and how it could survive in spite of continual failure of concrete projects. 
Umbrella promises are open-ended and can remain very general in nature. A variety of more specific promises can be subsumed under these 'umbrella' promises. They are primarily a discursive phenomenon, and offer narratives linking a new field to broad problems like competition in the world economy, and societal and global issues like climate change. Such narratives fit into the recent policy discourse of 'grand challenges' (Lund Declaration 2009), and legitimise the relevance of the promise to the wider world. Occasionally also concerns about technologies getting out of control are voiced in such narratives. When accepted, an umbrella promise (and sometimes black-boxed through the use of an umbrella term like 'nanotechnology') functions as protection of more specific promises and whatever happens on the ground. ${ }^{6}$ To maintain their relative freedom, actors may well be reluctant to specify further the open-ended and diffuse promise.

In the particular constellation of the present regime of economics of techno-scientific promise there is a further dynamic: the supply and demand of promises (Joly, Rip, and Callon 2010). Narratives and visions are formulated by scientists who need to mobilise resources. Eventual realisation of their vision is only one and sometimes only a minor goal. At the side of policy and politics there is a demand because policy actors have to fill a portfolio of interesting initiatives and priorities to gain political support for their role and to justify spending on R\&D. The producers of narratives and visions, scientists or other actors, may anticipate political agendas and strategically formulate umbrella promises. If successful they become part of what $\operatorname{Konrad}(2006,431)$ calls a 'generalised and taken-for-granted social repertoire' (of promises and promising). Joly, Rip, and Callon (2010) emphasise how promises are presented so as to create a sense of urgency: referring to the need not to lag behind in competitive environments (scientific, technological and economic) and/or the need to address 'grand challenges'.

The open-ended umbrella promises become embodied in the form of activities, like funding decisions and their justification, emerging networks and attempts to improve coordination of technology development and application. These are material indicators of their existence and importance, see Van Lente (1993, 193).

\section{Promise-requirement cycles}

Promises can be more specific, i.e. be formulated in terms of a concrete performance that might be realised, or an actual demand that might be met. These are then translated into requirements on further development. Resources can be dedicated to realise the requirements. After a first round of development work and evaluation of results, specific obstacles and/or specific expectations will be identified and again translated into requirements on further work. Activities to address these requirements will often occur in a 'protected space', an environment which is relatively shielded from outside scrutiny. Expectations actually support the creation of such 'protected spaces'. This succession of promises, requirements, ongoing work and more specific promises and related requirements (a promise-requirement cycle; Van Lente 1993) continues until a working artefact or system is realised. It may be stopped prematurely if progress is disappointing.

Thus, the promise-requirement cycle creates a trajectory of development. At each turn of the cycle decisions have to be taken - necessarily based on expectations - whether to continue to explore or whether to be more focused. Overall, the trajectory moves from requirement-constrained exploration of an option to a focus on exploitation (March 1991; Verganti 1999). By then, other perhaps also viable options might be neglected or become less important. $^{8}$ 


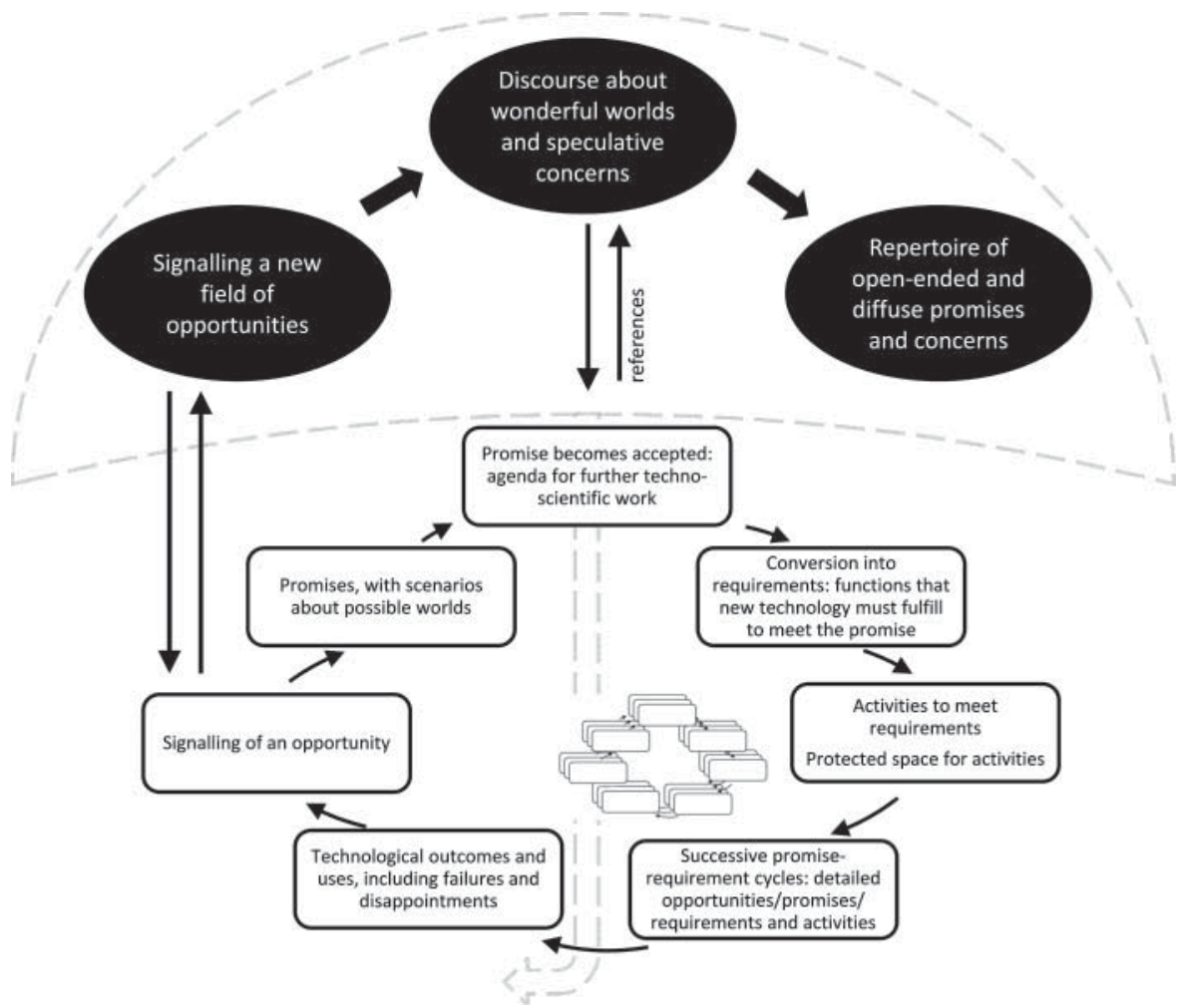

Figure 1. Dual dynamics of promises.

\section{Dual dynamics of promises}

The two dynamics are not independent. Promise-requirement cycles can and will refer to the umbrella promise for legitimation, and the umbrella promise may want to draw on some successful realisations to remain credible. To capture such dual dynamics of promises, Figure 1 visualises the dual dynamics. The basic coupling is how the signalling of a promising option, say a new nanostructured material, is linked to the signalling of a new field of opportunities like nanotechnology in general. The key question in further interactions is whether the success or failure of concrete projects are blamed on the umbrella promise or on circumstances (cf. Rip 2012).

Different patterns can emerge. We have summarised patterns in dual dynamics in Table 1 and highlighted the different role umbrella promises play in relation to more concrete promiserequirement cycles. We will zoom in on the pattern of 'waiting games', where the reluctance of actors to invest in concrete developments, while they continue to refer to the umbrella promise, has become like a rule of the game.

\section{Waiting strategies}

Before we discuss the pattern of a waiting game, we must consider waiting strategies of actors, as these can be followed without there being a waiting game. For example, the recurring waiting strategy of big pharmaceutical companies to not invest in exploratory $R \& D$ and lateral innovation, 
Table 1. Different patterns in dual dynamics of promises of emerging technologies.

\begin{tabular}{|c|c|c|c|c|}
\hline & $\begin{array}{l}\text { Hype-disappointment } \\
\text { cycles }\end{array}$ & Promise icons & Priority setting & Waiting games \\
\hline Dynamics & $\begin{array}{l}\text { While actors } \\
\text { are concerned } \\
\text { about possible } \\
\text { disappointment, } \\
\text { exaggeration } \\
\text { is perceived to } \\
\text { be inevitable to } \\
\text { create visibility } \\
\text { and attract } \\
\text { funding. Umbrella } \\
\text { promises are } \\
\text { hype-friendly. }\end{array}$ & $\begin{array}{l}\text { Concrete technology } \\
\text { developments } \\
\text { refer back to } \\
\text { umbrella promises } \\
\text { which remain } \\
\text { unchecked. } \\
\text { Success in } \\
\text { developments } \\
\text { is attributed to } \\
\text { the 'force' of the } \\
\text { umbrella promise, } \\
\text { while failure is } \\
\text { related to other } \\
\text { factors. }\end{array}$ & $\begin{array}{l}\text { Umbrella promises } \\
\text { invite priority } \\
\text { setting and funding } \\
\text { (related to grand } \\
\text { challenges). Long- } \\
\text { term goals are } \\
\text { more important } \\
\text { than concrete } \\
\text { innovation. }\end{array}$ & $\begin{array}{l}\text { Appealing umbrella } \\
\text { promises keep } \\
\text { actors 'in the } \\
\text { game', while } \\
\text { uncertainties about } \\
\text { demand from users } \\
\text { and uncertainties } \\
\text { about specific } \\
\text { technology } \\
\text { directions make } \\
\text { the interdependent } \\
\text { actors reluctant } \\
\text { to take concrete } \\
\text { action. }\end{array}$ \\
\hline Outcomes & $\begin{array}{l}\text { Big umbrella } \\
\text { promise eventually } \\
\text { collapses, a shake- } \\
\text { out occurs, work } \\
\text { continues on the } \\
\text { few technologies } \\
\text { that show concrete } \\
\text { promise. }\end{array}$ & $\begin{array}{l}\text { Umbrella promises } \\
\text { survive, despite } \\
\text { failures in concrete } \\
\text { technology } \\
\text { developments } \\
\text { which refer back } \\
\text { to them. }\end{array}$ & $\begin{array}{l}\text { With their partial } \\
\text { institutionalisa- } \\
\text { tion, umbrella } \\
\text { promises provide } \\
\text { stable backdrop for } \\
\text { agenda-building } \\
\text { and acquisition of } \\
\text { funding. }\end{array}$ & $\begin{array}{l}\text { Actors recognise } \\
\text { umbrella } \\
\text { promises, but } \\
\text { will not take the } \\
\text { risk of investing } \\
\text { heavily in concrete } \\
\text { developments. }\end{array}$ \\
\hline $\begin{array}{l}\text { Empirical } \\
\text { examples }\end{array}$ & $\begin{array}{l}\text { Hype-cycle } \\
\text { introduced by } \\
\text { Gartner Group for } \\
\text { ICTs; hype-cycles } \\
\text { as part of 'folk } \\
\text { theories' about } \\
\text { nanotechnology } \\
\text { (Rip 2006). }\end{array}$ & $\begin{array}{l}\text { Electronic super } \\
\text { highway (Konrad } \\
\text { 2004). }\end{array}$ & $\begin{array}{l}\text { European Technol- } \\
\text { ogy Platforms } \\
\text { (ETPs) such } \\
\text { as ETP } \\
\text { Nanomedicine } \\
\text { (this paper) }\end{array}$ & $\begin{array}{l}\text { Impasses in OLAE } \\
\text { and drug delivery } \\
\text { (this paper) }\end{array}$ \\
\hline
\end{tabular}

relates to their sunk investments in the business model of blockbusters, and their power to buy into eventually interesting developments realised by small firms and/or public research groups, at a later stage when the promise is more definite. ${ }^{9}$ It is a symbiosis game, and some start-up R\&D companies in the sector actually say in their business model that their aim is eventually to sell out to a big pharmaceutical company.

Waiting strategies can be the result of firm-internal decisions estimating costs and benefits of taking different timing decisions. ${ }^{10}$ For example, postponing in order to avoid the costs of learning at an early stage, or conversely, obtaining a competitive advantage by getting ahead on the learning curve. For novel and possibly disruptive technologies, such assessments are difficult to make: there is lack of a common technological frame; there are no established networks; and no standards and infra-technology (Tassey 1991). The new product development literature (e.g. Mullins and Sutherland 1998) has emphasised that in transient and turbulent environments decision makers will inevitably have difficulty in estimating the amount of resources that should be committed in the face of market uncertainty as well as the timing with which such resource commitments should be made available. 


\section{Waiting games}

In the situation of a waiting game, the reluctance of different actors to invest effort and money is not a matter of individual decisions which happen to gravitate towards little or no investing. There are mutual dependencies and informal rules which are being followed, so it is a game, played by real actors. '[A] game exists if courses of action are in fact interdependent, so that the outcome achieved will be affected by the choice of both (or all) the players' (Scharpf 1997, 7).

Specific for the waiting game linked to promises around NEST is the appeal of the umbrella promise which requires actors to pay some attention. Even in cases where there is little involvement, as with big pharma in the area of nano-enabled drug delivery systems, they still want to monitor developments closely (as their researchers and strategy staff do anyway). Therefore, actors choose not to exit the game. The umbrella promises remain on the radar of various actors even if little actual developments take place.

There are further features of this kind of waiting game, like the fact that producing and circulating open-ended promises need not require much dedicated investments (although that depends on the target audience). The repertoire of promises can remain alive without much effort.

More important is the combination of two types of uncertainties: at the development and supply side and at the user and demand side. At the user side there is little incentive to articulate specific demands (to be met by the developers/suppliers) because it is unclear in which direction the technology will develop, and which performance can actually be achieved. At the supply side, the uncertainty about demand creates reluctance to choose pro-actively for one or another development, even when it is recognised that one must at one moment shift from exploration to exploitation. There is no 'solution', other than one or another actor being willing to stick out its neck and take a risk - and this happens occasionally. Firms, for example in the ICT sector, have been willing to introduce products for which demand was still unclear. Users may commit themselves to accept a product to be developed, as when governments go for procurement to stimulate technological innovation (Edler and Georghiou 2007; Georghiou 2007).

Thus, waiting games may be overcome. Actors actually consider possibilities for this to happen and can discuss strategies in order to change what they perceive as an undesirable situation. ${ }^{11}$ One way is coordination of emerging technologies (cf. the discourse of European Technology Platforms). Another way is the establishment of novel institutions to reduce uncertainties (Te Kulve 2010). Such moves themselves require investing in a 'collective good', and actors may well be reluctant to do so. In our empirical and scenario work we identified attempts by actors to overcome waiting games and saw how difficult it was for them to gather sufficient momentum to make a difference.

\section{Case studies}

The concept of waiting games, linked to the dual dynamics of promises, will structure our case studies of two domains of development in the broad field of nanotechnology. ${ }^{12}$ Promises can be made for the broad field as a whole. In our two case studies we will focus on identifying the umbrella promises specific to each of the two domains, and trace how they function.

The second step in our analysis is to check for reluctance to invest in concrete developments, so that there will be few and/or only partial promise-requirement cycles. In a third step, we trace the constellation of mutual dependencies and thus specifics of the waiting game in that domain, and consider how actors are coping with waiting games. 
The two cases are interestingly different. The drug delivery sector is an intersection between two specific value chains, drug development and formulation and device development, to serve an end market. The role of nanotechnology is enabling: it will improve what is done already, and only occasionally introduce new functionalities. OLAE on the other hand, as a new field of opportunities, can serve many different value chains, and the range of technological options, niche developments and relevant actors is much larger. In the case of OLAE we see all the elements and dynamics of a waiting game linked to dual dynamics of promises. Nano-enabled targeted drug delivery on the other hand is not a new field, even if there are new options. Other interactions and other responses to the waiting game will be visible there, compared with the OLAE case.

\section{Organic large area electronics}

OLAE is a technology platform and as such opens up a new field of varied opportunities. ${ }^{13}$ The discovery of organic semi-conducting materials (Shirakawa et al. 1977) led to visions about the use of conjugated organic molecules and organic/inorganic composites to conduct current, emit light, and act as semiconductors, and to exploit the mechanical properties (flexibility) of these materials. This would create a shift from present silicon and lithography based manufacturing in the electronics industry to potentially cleaner, more flexible and cost effective manufacturing processes like printing (Shaw and Seidler 2001). One effect might be that printer manufacturers and printing industry would make their entry in the electronics industry - a change in industry structure.

Since the 1970s the focus of activities has been on R\&D to improve performance of the materials. Starting in the 1980s, effort was also invested in making useful working organic semiconductor devices. By now, there is recognition that complementary innovations are necessary, and further actors enter the world of OLAE. In addition to printing, new manufacturing technologies, process equipment, and encapsulation techniques have proven to be important.

The electronic and material properties of the new materials led to visions of a wide range of new products, but with little interaction with, or anticipation on end users. At the moment, the domain of OLAE is still a world in which technology-linked relationships among actors dominate. Business to business relationships are explored, and 'new combinations' are formed across traditional value chains.

\section{Umbrella promise}

The umbrella term OLAE is used when linking the broad vision of technological opportunities with significant societal themes like global warming (alternative energy, higher efficiency devices), increasing mobility (light weight, increasing functionalities) and embedded intelligence (low cost sensing and RFID). This is visible in the text and title of the recent (2009) strategic research agenda of OLAE presented to the European Commission. ${ }^{14}$ The rhetorically powerful title 'Towards green electronics' went together with reference to a potential market of $\$ 300$ billion to be realised by 2027.

There are promises about the disruptive functionalities by authorities like Sir David King, former UK government chief scientific advisor:

In Britain we have a world-leading position in a technology that could wipe out silicon chip technology and could convert photovoltaics into easily accessible materials at a much cheaper price, and I am talking about plastic electronics. (House of Commons 2009, 1) 
Current policy narratives are mobilised to create a sense of urgency, including the maintaining of a leadership position in the face of increasing competition:

Organic and Large Area Electronics is one of the most promising areas in the field of electronics.... the potential of this disruptive electronic area, which is predicted to reach a market size of about $\$ 10$ billion in 2010 and grow exponentially thereafter until acquiring a market size equivalent to that of the silicon.... The cost-effectiveness of this technology for large area (unlike silicon) is acting as a catalyst. And the fact that the whole technology can be added on flexible plastic foils has also been a powerful driver for this field. ... Concerning sustainable development, the advances could also be noticed in many areas.... Europe has a strong position and expertise in organic and large area electronics which derives from the number of academia institutions working in the area, ahead of East Asia and North America. (European Commission 2008, 14)

Industry analysts warn of the danger for Europe to lose the race (Harrop 2007). The chairman of IDTechEx highlighted this as a possible conclusion of IDTechEx's report 'Organic and Printed Electronics in Europe': 15

Overall, Europe may be losing the race for the huge new business of printed electronics and the rejuvenation of society that it will bring. This is despite having far more academic institutions than

East Asia working on the subject, the number being somewhat ahead of North America as well.

Such forecasts construct an economic interest in the field of OLAE, which is then replayed in policy documents. But there are also warnings about inflated expectations that cannot realistically be achieved, from influential consultancies like Cintelliq. ${ }^{16}$

The underlying assumption in this discourse of disruptive technologies (specified as printed RFID, cheap and disposable point-of-care devices, organic photovoltaics and OLED for displays and lighting) is that progress along learning curves will be rapid enough to overtake existing technologies (cf. Christensen 1997). However, this assumption remains unchecked, while one may be doubtful because of the complexities involved in crossing value chains, complementary technologies and acceptance by users.

\section{Reluctance to invest in product development}

In our interviews and document analysis, the contrast was clear between hopeful research, conferences and consortiums to mobilise support for OLAE, and the absence of concrete strategies and investment in product development. There is an abundance of options but no easy way to select for exploitation in actual product development. The conclusions of the Organic Electronics Association $(2008,5)$ emphasise this, when they say that it is not possible to define a 'Moore's Law' for organic electronics, or to define any killer applications - so there are no simple incentives to invest in specific product development.

Actors are concerned about lack of interest from end users. ${ }^{17}$ At a stakeholder meeting organised by the European Commission in 2007, Wolfgang Clemens, Director of Organic Electronics Association (which represents more than 70 companies active in the field of OLAE), emphasised that 'End-users do not know enough about possibilities of the technology' and proposed to educate end users (Clements, Mildner, and Hecker 2007, 15). A competence matrix study on plastic electronics in the UK concluded: 'There is no incentive for companies to develop compatible standards or push for common technology platforms without a powerful end-user to insist on this' (King 2008). 
The combination of lack of articulated demand (with end users, but also with business customers) and lack of articulated directions for product development creates a situation where actors are reluctant to invest. This is made explicit in an interview in an industry magazine with Martin Schmitt-Lewen, manager of functional printing at Heidelberg Company:

I can't see Heidelberg commercially printing electronics or developing the equipment for a long while yet and there is no point in developing a printing kit or system when there are no existing customers ready to buy them, considering very few companies in the printed electronics market are scaling up production, particularly in RFID and active packaging space, there is no requirement for large print press systems.

He argues further in this interview,

We want to avoid speculatively developing equipment or printed electronics products until the technology and the market are more mature. (Anonymous 2009, 37)

This is not just a risk averse approach. If it were, Heidelberg Company would not bother, and just exit. Nevertheless, it maintains a presence in the OLAE world, just in case. Many innovation actors do so, for example by being involved in public or semi-public projects, conferring symbolic support to R\&D in the field. They may be reluctant to invest, but are also on the look out for opportunities to do something.

\section{Constellations in the waiting game}

There are actual and projected mutual dependencies which shape strategies and patterns of interaction. Upstream actors like materials suppliers, printer manufacturers and ink producers are a key example.

Materials are crucial for device performance. Exploring the qualities of specific ink jet techniques requires printer manufacturers to form new alignments with material suppliers and ink manufacturers (Cleland 2003, 108); but there are conflicting business models.

The use of materials in the printing technologies for the production of a printed OLED or organic transistor is much less than in the traditional deposition technologies. Chemical suppliers are used to sell large volumes of materials, but in the new situation they must adapt their pricing strategies. ${ }^{18}$ They must also learn to produce for niche applications of organic electronics. Chemical suppliers may not make these moves of their own accord.

Uncertainty about value capture and profitability, a general issue, is felt in the printing industry. At present, the ink jet printing industry is profitable because of the sales of ink supplies rather than of printers. ${ }^{19}$ The industry may want to become pro-active as existing patents on OLED materials will soon expire. ${ }^{20}$ Ink-jet companies may then leverage economic advantage by formulating own materials or partnering with firms that have the capability to do so (Cleland 2003, 108). Alternatively, new entities may emerge in the value chain, like design houses for products with different specifications. This is a realistic option only when a global capacity for dedicated production is in place and some standardisation has occurred. ${ }^{21}$ Therefore, the waiting game may strike again: there are no incentives to invest in building up such a capacity and creating standardisation.

While there is a lot of work in the field of organic electronics on improvement of materials performance, requirements derived from downstream applications get less attention. One such challenge is encapsulation, a critical problem in realising organic electronics products because organic materials are highly sensitive and fragile and deteriorate when exposed to oxygen and moisture (Patterson 2009, 160-3). Lack of adequate encapsulation techniques and materials constitutes a reverse salient for the further expansion of OLAE. ${ }^{22}$ Dedicated work on the reverse 
salient is like producing a collective good, and return on such an investment will materialise only when the expansion of OLAE applications is achieved. To overcome this version of the waiting game, action at the collective level may well be necessary.

This diagnosis of the situation was actually taken up in one of the scenarios we created for further development of OLAE and its embedding in society. ${ }^{23}$ We had the UK government initiate a procurement policy to give OLAE a boost: development of new RFID-based electronic passports and guaranteeing their use (this is procurement policy). Some other countries sensitive to terrorism joined the initiative. Eventually, the technical performance was insufficient to guarantee privacy, and the project was stopped. However, the challenge of encapsulation had had to be met, and effective materials and techniques were now available generally. Others could profit, for example in the government-supported development of organic photovoltaics in Germany. In so far there is a moral to this scenario; it is that collective-level actors can play an important role, but that the challenge of the reverse salient of encapsulation was (partially) resolved as a by-effect of a procurement project, rather than addressed as such.

\section{Nano-enabled drug delivery systems}

Drug delivery systems, including nanotechnology enabled systems, are part of the formulation stage of drug manufacturing. A drug delivery system is a formulation or device 'that delivers therapeutic agent(s) to desired body location(s) and/or provides timely release of therapeutic agent(s). The system, on its own, is not a therapy, but improves the efficacy and/or safety of the therapeutic agent(s) that it carries'. ${ }^{24}$

The drug delivery sector is an intersection of two product value chains, drugs and delivery. The value chain of drug development involves large pharmaceutical companies that have their focus on developing new chemical entities rather than novel formulations (Breimer 1999); the latter are outsourced to drug delivery product companies, cf. De Leeuw, de Wolf, and van den Bosch (2003). The drug delivery sector was dominated by the customer-oriented pharmaceutical companies, but the new interest in carriers has enabled drug delivery companies to become somewhat independent of the pharmaceutical world. ${ }^{25}$ Nanotechnology enables this sector to do better, and is not seen as disruptive: it can create new functionalities, but basically focuses on maximising drug effectiveness through controlled release and accuracy in reaching targets.

The increased academic interest in nanotechnology-enabled drug delivery is visible in the steep rise of research papers and patents since early 2000s (Kim et al. 2009). The rise in research funding for the combination of nanotechnology and drug delivery, predicated on the promises of nanotechnology, has given the field of drug delivery research a new impulse (cf. Boyd 2008). With its focus on coordination, the European Technology Platform (ETP) Nanomedicine actively promotes developments of nano-enabled drug delivery systems.

\section{Umbrella promise}

The 2005 vision paper of the ETP Nanomedicine sets out the promises, starting with the general promise of nanotechnology including the promise of nanoparticles to reach their targets as if they were a magic bullet. ${ }^{26}$ They characterise nanotechnology as a crucial enabler to reach goals in the medical and health care sector:

The long-term objective of drug delivery systems is the ability to target selected cells and/or receptors within the body. At present, the development of new drug delivery techniques is driven by the need 
on the one hand to more effectively target drugs to the site of disease, to increase patient acceptability and reduce healthcare costs; and on the other hand, to identify novel ways to deliver new classes of pharmaceuticals that cannot be effectively delivered by conventional means. Nanotechnology is critical in reaching these goals. (ETP Nanomedicine 2005, 8)

At the same time, a sense of urgency is created by referring to the narrative of competition (e.g. 'Europe has a strong position'; the need to 'boost this promising field'), leading to a call for close collaboration in research activities in the field of nanomedicine:

At present Europe has a strong position in the emerging field of NanoMedicine that has a high potential for technological and conceptual breakthroughs, innovation and creation of employment. NanoMedicine is an area that would benefit from coordination at European level. Thus, close cooperation between industry, research centres, academia, hospitals, regulatory bodies, funding agencies, patient organisations, investors and other stakeholders could dramatically boost this promising field. In response to these challenges, scientific experts from industry, research centres and academia convened to prepare the present vision document regarding future research priorities in NanoMedicine. (ETP Nanomedicine 2005, 5)

The dual dynamics pattern of 'priority-setting' is visible here. The umbrella promise is referred to widely in the literature and in declarations at conferences and in the media. Nanotechnologies are considered to have 'unique qualities' (Emerich and Thanos 2006) and provide 'extraordinary opportunities' to contribute to targeting problems for major diseases such as cancer therapies (Ferrari 2005). In addition, nanotechnology enabled drug delivery technologies are also expected to contribute to finding medicine to treat other diseases such as infections, metabolic and autoimmune diseases (Couvreur and Vauthier 2006).

While the general promise is recognised, and considered important, there are also sceptical comments on how far the nanotechnology enabled targeting has actually advanced (Ruenraroengsak, Cook, and Florence 2010), and whether existing carriers and approaches might be good enough already. At conferences and in interviews (by one of us, HtK), nanotechnologies were often considered to be not very attractive to develop in-house. Promises that nano-enabled drug delivery might extend the life-cycle of drugs (by allowing further patenting) were met with scepticism. In terms of performance, the promised improvement of existing medicines, e.g. by increasing bioavailability or improving of the dosage regime, might not be so attractive, as therapeutical gains were expected to be limited and nanotechnologies would have to compete with well-developed conventional approaches. Delivery of new active compounds such as biopharmaceutical entities and disease targeting were considered to be more promising (Wagner et al. 2006; Keller 2007; Boyd 2008).

\section{Reluctance to invest in product development}

In spite of the general need for new pharmaceutical technologies by pharmaceutical companies, they do not regularly involve themselves in nano-enabled drug delivery research projects or in broad stakeholder fora such as the ETP Nanomedicine. ${ }^{27}$ Researchers working on nanotechnology-enabled drug delivery technologies complain about this lack of interest. The EU-funded consortium MediTrans is explicit in its diagnosis how this impedes the introduction of nanotechnologies in the clinic.

It is now well known that a reliable targeting system is essential for successful drug delivery in many serious disease situations. It is becoming increasingly recognised that a major limitation, impeding the entry of targeted delivery systems into the clinic, is that new concepts and innovative research ideas 
within academia are not being developed and exploited in collaboration with the pharmaceutical industry. Thus, an integrated "bench-to-clinic" approach realised within a structural collaboration between industry and academia, is required to safeguard and promote the progression of targeted nanomedicines towards clinical application. (MEDITRANS 2007a, b)

While big pharmaceutical companies are interested in innovative medicines, ${ }^{28}$ they do not invest in nanotechnology-related research. Director Keller from GlaxoSmithKline mentioned during a conference on Medical Nanotechnologies that they 'recently had shut down their department as it was not the time to create a nano department' (Keller 2007).

There appear to be two waiting strategies involved. The main one derives from the overall promise of nanotechnology and assessment of the more specific promises about nano-enabled targeted drug delivery, as convincing enough to start to invest. This is then compounded by big pharma's focus on drugs, i.e. active compounds rather than formulations and or delivery systems and it is linked to their general waiting strategy: let others take the risk of novel approaches. Big pharmaceutical companies such as GlaxoSmithKline and AstraZeneca preferred to co-operate with other parties rather than doing development themselves (Keller 2007; Washington 2007). ${ }^{29}$

In their review of technological and commercial developments, Couvreur and Vauthier (2006) pointed out that a 'confident climate' for new nanosystems has to be developed on the basis of already positive experiences (both clinically and in regulatory terms) of such systems. Nevertheless, they also observed reluctance of large pharmaceutical companies towards nano drug delivery: 'Today, most developments are carried on by small entrepreneurial firms including many spin-ups that cannot support themselves as yet on current revenues, whereas big pharmaceutical companies seem still awaiting for more successes'. Wagner et al. (2006) speculated that firms were waiting for the first nano blockbuster before they would initiate heavy investments in this area.

In response to this waiting game, researchers and other promoters of nanomedicine in general, and nano-enabled targeted drug delivery in particular, moved from general promises to more specific ones, in the hope that this would lead to investment in actual development. This is visible in the 2009 Roadmap Document of the ETP Nanomedicine. Recommendations were offered, and to persuade industry there was a veiled reference to a possible loss of competitive position in the global market:

\footnotetext{
The Strategic Research Agenda of the ETP Nanomedicine was drafted in 2006 with a broad range of options highlighted. Over the intervening years it has become increasingly clear to the industrial sector that an academic driven or laissez-faire approach to Nanomedicines will be an inefficient process. It is recognised that it is now time to make more detailed specific recommendations [..] Successful translation of research results from academia into products has been identified to be one of the major challenges in this innovative science based area. Strategies to foster and initiate this translatability must be developed and implemented to help European research and industries remain competitive in the global market. (ETP Nanomedicine 2009, 4)
}

There continues to be support for $\mathrm{R} \& \mathrm{D}$, and public interest has not disappeared, but actual product development remains limited (Te Kulve 2011).

\section{Constellations in the waiting game}

There might be symbiotic relationships: '(..) smaller companies and start-ups rely on partnering with big pharma that provide funding for the clinical trials' (Wagner et al. 2006, 36). The involvement of big pharma would bring in knowledge and experience with respect to development 
and regulatory processes (Eaton 2007). Not much is happening in practice, also because of uncertainties about intellectual property rights.

A key aspect of the constellation is the regulatory set-up. Regulation of new drugs and drug delivery systems has well-articulated procedures, and for new drugs quite elaborate and costly, because new drugs are approved after going through pre-clinical and clinical tests, this also puts constraints on what can then be changed in terms of formulation without doing further studies (Washington 2007). For nano-enabled drug delivery systems which bridge drug, device and formulation development, it is not clear how regulatory processes will work out, also because of uncertainties about standards and methodologies for assessments of new nano-enabled technologies. Authorities will wait until they know which technologies are under development before checking whether existing procedures are adequate, or modifications are in order. Drug delivery and pharmaceutical companies will not develop new products if there is no assurance about regulatory requirements.

At the moment, the key challenge is the gap between the enthusiasm of researchers and other promoters of nano-enabled targeted drug delivery systems, justified in terms of umbrella promises, and the reluctance of clinical actors and pharmaceutical companies to involve themselves in the development of such systems. One visible strategy from the side of the promoters is to shift from pushing their 'magic bullets' to emphasise the need for translational research (Te Kulve 2011). In doing this, they relate to a general move in this direction in nanomedicine, and in pharmaceutical research generally.

Possible next steps were explored in scenarios. ${ }^{30}$ A key move to break through the waiting game was coordination through platforms and consortia together with other actors in the value chain, up to patient organisations. Depending on how the interventions were received and had to be modified, different (and contested) development paths were pursued. One route was to go for the 'safe' option of liposomes and other biodegradable carriers. Cancer therapies, another route and one which had captured media attention, turned out to be quite complex, and lead to niche applications at best.

\section{Conclusion}

The case of nano-enabled targeted drug delivery is interesting because the waiting game linked to dual dynamics of promises is additional to the general waiting strategies of big pharma with respect to novel approaches. The case of OLAE is interesting because of the potentially disruptive character of OLAE, so that actors are at a loss which directions to take. Thus they fall back on the safe option (in the short term) to wait and see.

A key feature of the two cases, and of NEST in general, is the combination of uncertainties about eventual performance and uncertainties about customer/user demands and requirements. There attempts to reduce uncertainties through new alliances and consortia, but the basic response of actors was reluctance to invest in concrete product development. The overall promises of OLAE and (to a lesser extent for some of the actors) of nano-enabled drug delivery were recognised, and in fact there was a quasi-certainty about them. OLAE will arrive, unavoidably so, even if 'we' have to put a lot of effort into realising the promise. This is what turned the situation into a waiting game: exiting the game, by forgetting about OLAE, is not an option.

If there are waiting games, there will be less development, and thus less learning about possibilities than could have been the case. Alternatively, the pause introduced by waiting games may become an occasion to reflect on desirable directions and alternatives, rather than falling for the sense of urgency induced by the umbrella promise. 
Waiting games around NEST appear to be unavoidable. However, innovation and policy actors driven by their sense of urgency, will see this situation as undesirable and will try to overcome the waiting game. ${ }^{31}$ They may not be successful, because actions at the collective level are necessary to break through waiting games, and these are difficult to achieve. A small step in the direction of doing better is provided by our scenario exercises and their discussion in strategy-articulation workshops with different stakeholders.

Thus, what we have done in this paper is more than observing and documenting a pattern, the pattern of waiting games that keep actors involved in the domain while this does not lead to much investment in concrete developments. We added an explanation in terms of dual dynamics of promising, showed that these dynamics were actually occurring, and explored some of the actual variety in the two cases that we presented. Since actors recognised there were waiting games (even if they need not think of explanations), we could also ask how they were coping, and perhaps trying to overcome the waiting games. Here, our understanding of constellations of actors and mutual dependencies could come in to help them become more effective, or at least, more reflexive.

\section{Notes}

1. The term 'halo' (around nanotechnology) was introduced by Vincent Bontems in a paper, 'How to accommodate to the invisible? Nano-impressionism', contributed to the workshop on 'Imag(in)ing the Nanoscale. Interactions between science, public media, and art', Bergen (Norway), 27-29 January 2011.

2. Ruef and Markard analysed such dual dynamics for one area of fuel cell development; they used the term 'frame' for what we called 'big but open-ended promises' (Ruef and Markard 2010).

3. In their analysis of economics of techno-scientific promises, Joly, Rip, and Callon (2010) discuss master narratives of promise, and how this drives policies, but do not recognise how this, paradoxically, can lead to waiting games.

4. Compare: 'The calculative agents on the idealised market of economic theory will identify possible "states of the world", rank them, and define choices and actions in those terms' (Callon 1998, 4) - which then change the current 'state of the world'.

5. The EC created ETPs as a general instrument in order 'to bring together all interested stakeholders to develop a longterm shared vision, create roadmaps, secure long-term financing and realise a coherent approach to governance'. (European Commission 2004, 10)

6. This point is emphasised by Rip and Voss (2011) in their analysis of umbrella terms like 'nanotechnology' and 'sustainability' in science and science policy.

7. Rip (2011) signalled a funding race (between states) for nanotechnology, rather than innovation races.

8. Van Merkerk and Robinson (2006) have discussed this as an example of emerging irreversibility, and linked it with the phenomenon of path dependency because of sunk investments.

9. Cf. Wagner et al. $(2006,36)$ highlighting big pharma's reluctance to invest in novel technologies in the field of biopharmaceuticals and nanomedicine.

10. See the seminal work by McDonald and Siegel (1986) and Pindyck (1991) and the literature on irreversible investments. Adoption (e.g. going for a particular development) can be viewed as a strategic switching-time decision problem for agents facing an ongoing stochastic operating benefit, plus sunk investment costs (Moretto 2000).

11. Ironically, calls of civil society groups for moratoria on the introduction of nanotechnologies like nanoparticles until their safety is ascertained, take the waiting game as a desirable situation.

12. The case material is based on extensive and detailed study of documents, interviews, observations which have been reported in Te Kulve (2011) and Parandian (2012). The diagnosis of waiting games was used to create scenarios showing repercussions of one or another attempt to overcome the waiting game, which were subsequently used in interactive strategy-articulation workshops with stakeholders in the domain (Te Kulve 2011; Parandian 2012).

13. The definitions of the new field have not stabilised and different adjectives are used, e.g. flexible, organic, large area, plastic and polymer electronics. The term OLAE is used more generally, as an umbrella acronym, to refer to a field of innovative opportunities of the various technologies and their possible applications.

14. Strategic Research Agenda Organic \& Large Area electronics. 2009. Final Version 1.4. Last retrieved 3 May 2011. http://www.photonics21.org/download/olae_sra.pdf 
15. This IDTechEx report analyses and compares the activities of 248 European organisations in the sector.

16. Cintelliq is an information service and technology consulting company for organic semiconductors.

17. This was emphasised by Tom Taylor, CEO of PETEC (UK), during a seminar on plastic electronics in May 2009 organised by the IET Microsystems and Nanotechnology Network and the Institute of Nanotechnology in London. Also in an interview with Michael Butler of Unilever (UK), with one of us (AP).

18. As Eliav Haskal director of lighting strategic partnership in Philips Company, noted (in an interview with one of us, $\mathrm{AP}$ ), for the short term they can charge premium prices to make up for the R\&D costs they make hoping to supply to mass markets in the future.

19. This point was emphasised by Hylke Veenstra, of OCE The Netherlands, during his presentation at the Conference 'Tomorrow's Electronics', Utrecht (The Netherlands), May 2009, and in an interview with one of us (AP).

20. Interview (by AP) with Professor Paul Blom - University of Groningen and Holst Centre, Eindhoven.

21. Interview (by AP) with Professor Andres Dietzel - Eindhoven University and Holst Centre, Eindhoven.

22. A reverse salient is a subsystem that blocks further expansion of the entire system, so that that improving other subsystems will not make a difference as long as the reverse salient is not overcome (Hughes 1983; Ortt and Dedehayi 2010).

23. Three scenarios were created to support interactive strategy articulation workshops with stakeholders about OLAE, one in Eindhoven (supported by Plastic Electronics Foundation) and a second one in Heidelberg (supported by InnovationLab $\mathrm{GmbH}$ ).

24. From http://www.drugdel.com/glossbot.htm

25. Delivery devices can not only be used as carriers for drugs but can also be applied for diagnostic (imaging) purposes and in the context of food, as carriers for nutraceuticals.

26. The notion of a 'magic bullet' (Zauberkugel) was introduced by Paul Ehrlich, more than a century ago, to characterise the nature of the newly developed chemical drugs.

27. Whereas the vision paper was signed by high-level managers of companies such as GlaxoSmithKline and Schering, no big pharmaceutical companies were present within the drug delivery working group of the ETP Nanomedicine.

28. A European Technology Initiative 'Innovative Medicines' has been created, co-ordinated by the European Federation of Pharmaceutical Industries and Associations (EFPIA). It eventually developed into a Joint Technology Initiative in which there was strong participation by large pharmaceutical companies (Innovative Medicines Initiative 2008).

29. Observations by one of us (HtK) during the conference Investing in Medical Nanotechnologies II, London 2007. See also, Earl (2007).

30. Three scenarios based on different interventions to overcome the waiting game were developed and discussed in a strategy-articulation workshop with stakeholders, January 2010, organised in collaboration with branch organisations Nefarma and NIABA.

31. In terms of Hirschman (1970), this is the 'voice' rather than the 'exit' option.

\section{Notes on contributors}

Alireza Parandian obtained a PhD degree from Delft University of Technology. His research was part of Technology Assessment program of the Dutch Nanoned R\&D consortium, focussing on methodology development contributing to the approach of constructive technology assessment.

Arie Rip is Emeritus Professor of Philosophy of Science and Technology at the University of Twente. He has a record of contributions to studies of science dynamics, technology dynamics, and constructive technology assessment. He directed the Technology Assessment program of the Dutch Nanoned R\&D consortium.

Haico te Kulve is a postdoctoral Researcher at the University of Twente. The topic of his PhD dissertation was anticipatory interventions and the co-evolution of nanotechnology and society. This research was part of Technology Assessment programme of the Dutch Nanoned R\&D consortium.

\section{References}

Anonymous. 2009. Between the lines: What is Heidelberg's real plan for printed electronics? Plastic Electronics Magazine 1, no. 6: 32-9.

Borup, M., N. Brown, K. Konrad, and H. Van Lente. 2006. The sociology of expectations in science and technology. Technology Analysis and Strategic Management 18, no. 3: 285-98. 
Boyd, B.J. 2008. Past and future evolution in colloidal drug delivery systems. Expert Opinion Drug Delivery 5, no. 1: 69-85.

Breimer, D.D. 1999. Future challenges for drug delivery. Journal of Controlled Release 62, nos. 1-2: 3-6.

Brown, N., and M. Michael. 2003. A sociology of expectations: Retrospecting prospects and prospecting retrospects. Technology Analysis \& Strategic Management 15, no. 1: 4-18.

Brown, N., B. Rappert, and A. Webster. 2000. Contested futures - a sociology of prospective techno-science. Aldershot: Ashgate.

Callon, M., ed. 1998. The laws of the markets. Oxford and Malden: Blackwell Publishers.

Clements, W., W. Mildner, and K. Hecker. 2007. WG2: Roadmap, barriers for market entry. Coordination: OE-A. Presentation at organics and large area electronics stakeholder meeting. 1 October 2007. Brussels: EU Commission. ftp://ftp.cordis.europa.eu/pub/fp7/ict/docs/events-3-20071001-wg2-activities-presentation_en.pdf (accessed March 2011).

Cleland, T.A. 2003. Printed electronics: The next inkjet revolution? Master Diss., Sloan School of Management at MIT.

Christensen, C.M. 1997. The innovator's dilemma: When new technologies cause great firms to fail. Cambridge, MA: Harvard Business Press.

Couvreur, P., and C. Vauthier. 2006. Nanotechnology: Intelligent design to treat complex disease. Pharmaceutical Research 23, no. 7: 1417-50.

De Leeuw, B.J., P. de Wolf, and F.A.J. van den Bosch. 2003. The changing role of technology suppliers in the pharmaceutical industry: The case of drug delivery companies. International Journal of Technology Management 25, nos. 3-4: 350-62.

Earl, P.M. 2007. Investing in medical nanotechnologies II - review. http://nanotechweek.blogspot.com/2007/12/investingin-medical-nanotechnologies.html (accessed 15 July 2009).

Eaton, M. 2007. Nanomedicine: Industry-wise research. Nature Materials 6, no. 4: 251-3.

Edler, J., and L. Georghiou. 2007. Public procurement and innovation - resurrecting the demand side. Research Policy 36, no. 7: 949-63.

Emerich, D.F., and C. Thanos. 2006. The pinpoint promise of nanoparticle-based drug delivery and molecular diagnosis. Biomolecular Engineering 23, no. 4: 171-84.

ETP Nanomedicine. 2009. Joint European Commission/ETP nanomedicine expert report 2009: Roadmaps in nanomedicine towards 2020. Available at http://www.etp-nanomedicine.eu/public/press-documents/publications/ etpn-publications (accessed April 2011).

European Commission. 2004. Communication from the Commission - towards a European strategy for nanotechnology. Luxembourg: Office for Official Publications of the European Communities.

European Commission. 2008. Project portfolio sixth and seventh research and development framework programmes: Organic and large area electronics. EU Commission: DG Information Society and Media. ftp://ftp.cordis.europa.eu/ pub/fp7/ict/docs/organic-elec-visual-display/olae-project-portfolio_en.pdf (accessed March 2011).

Ferrari, M. 2005. Cancer nanotechnology: Opportunities and challenges. Nature Reviews Cancer 5, no. 3: 161-71.

Georghiou, L. 2007. Demanding innovation. Lead markets, public procurement and Innovation, NESTA provocation 2, February 2007. London: National Endowment for Science, Technology and the Arts.

Harrop, P. 2007. Is Europe losing the race? IDTechEx. Printed Electronics World. http://www.printedelectronicsworld. com/articles/is_europe_losing_the_race_00000669.asp?sessionid=1 (accessed May 2011).

Hirschman, A.O. 1970. Exit, voice, and loyalty: Responses to decline in firms, organizations, and states. Cambridge, MA: Harvard University Press.

House of Commons. 2009. Innovation, universities, science and skills committee - fourth report: Engineering: Turning ideas into reality. Part 3, Plastic electronics engineering - innovation and commercialization. UK: House of Commons. http://www.publications.parliament.uk/pa/cm200809/cmselect/cmdius/50/5006.htm\#note74 (accessed March 2011).

Hughes, T.P. 1983. Networks of power: Electrification in western society, 1880-1930. Baltimore, MD: The John Hopkins University Press.

Innovative Medicines Initiative. 2008. Boosting biomedical research across Europe. Kick-off of a new public-private partnership for research funding. http://imi.europe.eu/docs/press-release-03032008_en.pdf (accessed 22 June 2010).

Joly, P.B., A. Rip, and M. Callon. 2010. Reinventing innovation. In The Governance of innovation. Firms, clusters and institutions in a changing setting, ed. M.J. Arentsen, W. Van Rossum, and A.E. Steenge, 19-32. Cheltenham, UK: Edward Elgar Publishing.

Keller, T. 2007. Nanotechnology: Cutting through the hype - a realistic business case for pharma. Paper presented at the Investing in Medical Nanotechnologies II, 28-29 November, Royal College of Surgeons, London. 
King, Z. 2008. Plastic electronics in the UK. (Lack of end-users is likely to constrain access to markets for UK SMEs). http://www.printedelectronics.net/PlasticElectronicsintheUK.htm\#1 (accessed March 2011).

Kim, S., I.K. Kwon, I.C. Kwon, and K. Park. 2009. Nanotechnology in drug delivery: Past, present, and future. In Nanotechnology in drug delivery, ed. M.M. De Villiers, P. Aramwit, and G.S. Kwon, 581-96. New York: Springer.

Konrad, K. 2004. Prägende erwartungen. Szenarien als schrittmacher der technikentwicklung. Berlin: edition sigma.

Konrad, K. 2006. The social dynamics of expectations: The interaction of collective and actor specific expectations on electronic commerce and interactive television. Technology Analysis \& Strategic Management 18, no. 3: 429-44.

Lund Declaration. 2009. Europe must focus on the grand challenges of our time, one result of the European research conference 'new worlds - new solutions', organised under the Swedish Presidency, Lund, 7-8 July 2009. http://www.se2009.eu/en/meetings_news/2009/7/8/declaration_from_the_research_conference_in_lund_european_ research_must_focus_on_the_grand_challenges (accessed May 2011).

March, J.G. 1991. Exploration and exploitation in organizational learning. Organization Science 2, no. 1: 71-87.

McDonald, R., and D.R. Siegel. 1986. The value of waiting to invest. The Quarterly Journal of Economics 101, no. 4: 707-28.

MEDITRANS. 2007a. State of the art. http://web.archive.org/web/20070504221129/http://www.meditrans-ip.net/Stateof-the-art.html (accessed 23 June 2010).

MEDITRANS. 2007b. Targeted delivery of nanomedicine: Project brochure 2007. http://www.meditrans-ip.net/files/ public/Meditrans_project_leaflet_2007.pdf (accessed 1 June 2010).

Moretto, M. 2000. Irreversible investment with uncertainty and strategic behavior. Economic Modelling 17, no. 4: $589-617$.

Mullins, J.W., and D.J. Sutherland. 1998. New product development in rapidly changing markets: An exploratory study. Journal of Product Innovation Management 15, no. 3: 224-36.

Organic Electronics Association. 2008. White paper OE-A roadmap for organic and printed electronics (May 2008 version). Frankfurt, German Engineering Federation (VDMA). http://www.novaled.com/downloadcenter/oe-a_roadmap_ white_paper_2008_may_public.pdf (accessed March 2011).

Ortt, J., and O. Dedehayi. 2010. Factors hampering technology system progress during the life cycle: What are these factors and how to deal with them? IAMOT Proceedings.

Parandian, A. 2012. Constructive TA of newly emerging technologies. Stimulating learning by anticipation through bridging events. PhD Thesis, Technical University of Delft.

Patterson, P. 2009. Beyond the beaker, how to achieve successful market adoption for emerging technologies. Beaverton, OR: Kohritsu Press.

Pindyck, R.S. 1991. Irreversibility, uncertainty, and investment. Journal of Economic Literature 29, no. 3: $1110-48$.

Rip, A. 2006. Folk theories of nanotechnologists. Science as Culture 15, no. 4: 349-65.

Rip, A. 2011. Science institutions and grand challenges of society: A scenario. Asian Research Policy 2, no. 1: 1-9.

Rip, A. 2012. Contexts of innovation journeys. Creativity and Innovation Management 21, no. 2: 158-70.

Rip, A., and J.-P. Voss. 2011. Umbrella terms in the governance of emerging science and technology: A nexus between science and society? Enschede/Berlin: University of Twente/Technical University of Berlin.

Ruef, A., and J. Markard. 2010. What happens after a hype? How changing expectations affected innovation activities in the case of stationary fuel cells. Technology Analysis \& Strategic Management 22, no. 3: 317-38.

Ruenraroengsak, P., J.M. Cook, and A.T. Florence. 2010. Nanosystem drug targeting: Facing up to complex realities. Journal of Controlled Release 141, no. 3: 265-76.

Scharpf, F.W. 1997. Games real actors play: Actor - centered institutionalism in policy research. Boulder, CO/Oxford: Westview Press.

Shaw, J.M., and P.F. Seidler. 2001. Organic electronics: Introduction. IBM Journal of Research and Development 45, no. 1: 3-9.

Shirakawa, H., E.J. Louis, A.G, MacDiarmid, C.K. Chiang, and A.J. Heeger. 1977. Synthesis of electrically conducting organic polymers: Halogen derivatives of polyacetylene, $(\mathrm{CH}) \mathrm{x}$. Journal of the Chemical Society, Chemical Communications, no. 16: 578-80.

Tassey, G. 1991. The functions technological infrastructure in a competitive economy. Research Policy 20, no. 4: 345-61.

Te Kulve, H. 2010. Emerging technologies and waiting games: Institutional entrepreneurs around nanotechnology in the food packaging sector. Science, Technology \& Innovation Studies 6, no. 1: 7-31.

Te Kulve, H. 2011. Anticipatory interventions and the co-evolution of nanotechnology and society. PhD Diss: University of Twente.

Van Lente, H. 1993. Promising technology. PhD Thesis, Twente University.

Van Lente, H., and A. Rip. 1998. Expectations in technological developments: An example of prospective structures to be filled in by agency. In Getting new technologies together. Studies in making sociotechnical order, ed. C. Disco, and B. Van der Meulen, 203-31. Berlin: Walter de Gruyter. 


\section{A. Parandian et al.}

Van Merkerk, R.O., and D.K.R. Robinson. 2006. Characterizing the emergence of a technological field: Expectations, agendas and networks in lab-on-a-chip technologies. Technology Analysis \& Strategic Management 18, nos. 3-4: 411-28.

Verganti, R. 1999. Planned flexibility: Linking anticipation and reaction in product development projects. Journal of Product Innovation Management 16, no. 4: 363-76.

Wagner, V., B. Hüsing, S. Gaisser, and A.-K. Bock. 2006. Nanomedicine: Drivers for development and possible impacts. Seville: Institute for Prospective Technology Studies.

Washington, C. 2007. Medical nanotechnology in the pharmaceutical industry: Opportunities and problems. Paper presented at the Investing in medical nanotechnologies II, 28-29 November, Royal College of Surgeons, London. 